\title{
Numb chin syndrome with sickle cell disease - a report of two cases
}

\begin{abstract}
Facial numbness localized to the region of the distribution of the mental nerve has been known as Numb Chin Syndrome (NCS) or mental nerve neuropathy. It is a rare clinical entity, very often associated with cancer. Sickle cell disease is an uncommon benign cause of NCS. We report here two cases of SCD with NCS in view of its rarity for the first time from India.
\end{abstract}

Volume 9 Issue 2 - 2019

\author{
PK Bariha,' KM Tudu, IMK Mohapatra, ${ }^{2}$ \\ Hemanta K Meher, ${ }^{3}$ S Rakesh Kumar, ${ }^{3}$ Anil K \\ Sahu ${ }^{3}$ \\ 'Asst.Professor, Dept of General Medicine, VSS Institute of \\ Medical Sciences and Research, India \\ 2Professor, VIMSAR, India \\ ${ }_{3}^{3}$ unior Resident, Dept of General Medicine, VIMSAR, India
}

Correspondence: Manoj Kumar Mohapatra, Prof. General Medicine, VIMSAR, India,

Email Mohapatra.manoj@rediffmail.com

Received: December 17, 2018 | Published: April 22, 2019

\section{Introduction}

Sickle cell disease is a haemoglobinopathy that is caused by a mutation in the $\beta$-globin gene that changes the sixth amino acid from glutamic acid to valine. ${ }^{1}$ It causes the polymerization of deoxygenated abnormal haemoglobin leading to morphologic alteration in erythrocytes that gives rise to different acute and chronic complications of the disease. Acute complications are commonly described as sickle cell crisis and commonly characterized by acute pain, tenderness in long bones, joints, fever, and tachycardia. ${ }^{1}$ Though symptoms of SCD are commonly found in long bones and soft tissues, rarely, can present as Numb chin syndrome (NCS) or mental nerve neuropathy (MNN). ${ }^{2}$ It is an infrequently recognised neurological entity that occurs due to damage of inferior alveolar nerve or its branch, mental nerve and is more often associated with cancer. ${ }^{3}$ The mental nerve neuropathy is one of the uncommon oral manifestations of SCD during or after acrisis. Few case reports of SCD with NCS are available in the literature, whereas none has been reported from India. ${ }^{4-9}$ In view of its rarity, we report 2 patients with sickle-cell disease with NCS.

\section{Case I}

An 18years old male patient with known history of sickle cell disease admitted with complains of bilateral hip joint pain, left knee joint pain with subsequent feeling of numbness of chin and lower lip and decreased sensation of touch in lower incisors and canine teeth (Figure 1). There was no cervical lymphadenopathy and other visible neck mass. Oral examination revealed normal soft tissue and salivary glands. Clinical examination showed absence of pain, touch and temperature sensation over mucous membrane and cutaneous portion of the entire lower lip. Sensation of the upper lip, gingiva and teeth appeared to be intact. The neurologic examination of other parts was normal. There was no restricted range of motion around bilateral temporo-mandibular joint. Laboratory tests showed Hb-6.8 gm/ $\mathrm{dl}$, total leucocyte count- $17300 / \mathrm{mm}^{3}$ ESR- 40 mm. All radiological imaging like X-ray of mandible, CT scan of brain with base of skull, MRI of brain and skull were within normal limits (Figure 2). X-ray chest PA view was normal. Ultrasound of abdomen and pelvis showed hepatomegaly and splenic infarction.

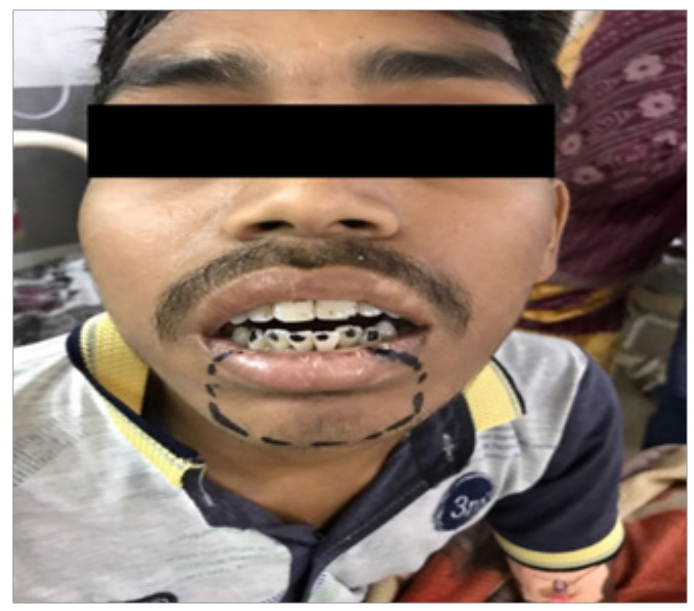

Figure I Showing zone of numbness in chin. B/L lower lip with buccal mucosa and gingival mucosa and lower incisor and canine teeth. 


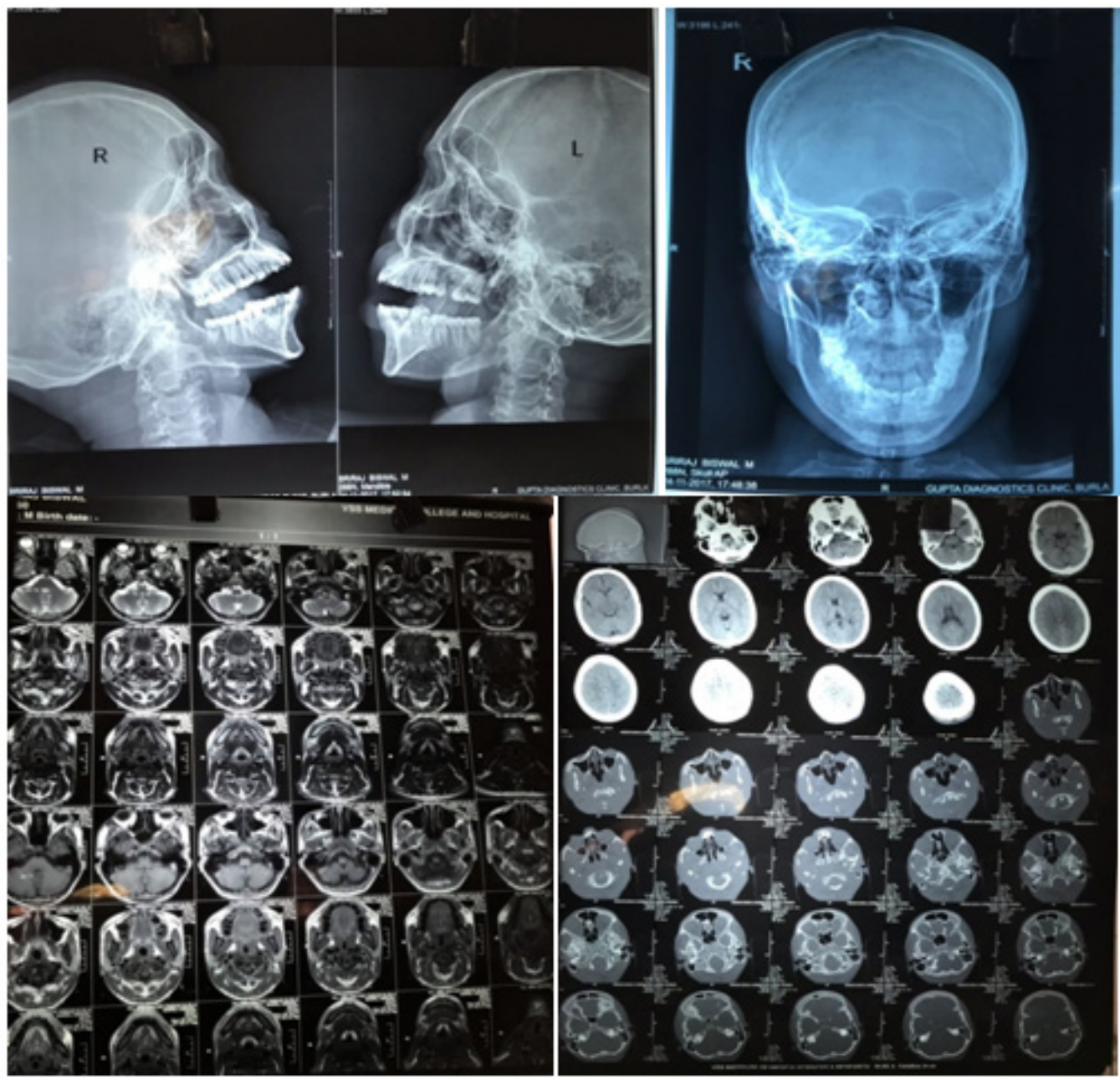

Figure 2 Showing Normal radiological imaging of skull, mandible, pranasal sinuses and brain parenchyma.

\section{Case 2}

A 38years old male with known history of sickle cell disease presented with numbness of chin, lower lip, and gingival mucosa in between two lower canine teeth (Figure 1). Dental sensation, upper lips, and other part of buccal mucosa sensations were intact He had prior history of admission to our hospital 1month back for painful crises and diagnosed as sickle cell disease by sickling slide test and $\mathrm{Hb}$ electrophoresis. His neurological examination revealed no abnormality in other parts of the body. Investigations showed, Hb.-6.1gm\%, total leucocyte count 21800per $\mathrm{mm}^{3}$ with neutrophil $84 \%$, Total platelet count 1.84 lacs per $\mathrm{mm}^{3}$. All other laboratory investigations were within normal limit. Radiological imaging including CT scan and MRI scan showed no specific abnormality.

\section{Discussion}

NCS is a rare clinical manifestation due to involvement of inferior alveolar nerve, a branch of posterior trunk of mandibular branch of the trigeminal nerve. The inferior alveolar nerve enters the body of the mandible through the mandibular foramen, traverses in the mandibular canal, and divides into mental and incisor branches. ${ }^{3}$ The mental nerve exits via mental foramen, in an unusual bending at the level of canine teeth, and supplies to the skin of the chin, lower lip, mucous membranes on the buccal surface of the lower lip, lateral gingiva, and teeth (Figure 3) (Figure 4). The classical NCS or MNN is the consequence of involvement of mental nerve that is characterized by hypoaesthesia, paresthesia, or thermo-analgesia of the chin and the lower lip, limited to the region supplied by mental nerve. Pain is less frequent and there is no taste or motor defect. It is usually unilateral but there may be bilateral involvement which can occur simultaneously or subsequently. Both the cases presented here had bilateral involvement and involvement of teeth. At times when inferior alveolar nerve is involved, the clinical pictures include the affection of teeth, gums, and the posterior half of mandible. ${ }^{3,4}$

The first case of NCS was described by Charles Bell in an elderly woman with breast cancer with mandibular metastasis compressing the inferior alveolar nerve. ${ }^{10}$ Subsequently, isolated case reports and case series have been published and most were associated with malignancies of which breast cancer and lymphomas are most 
common. ${ }^{3}$ However, it may be due to virus infection (especially human immunodeficiency virus), Lyme disease, syphilis, postvaccinal vasculitis, giant-cell arteritis, connective tissue diseases, amyloidosis, sarcoidosis, and diabetes. Dental procedures and dental anaesthesia can also cause NCS. ${ }^{3,4}$

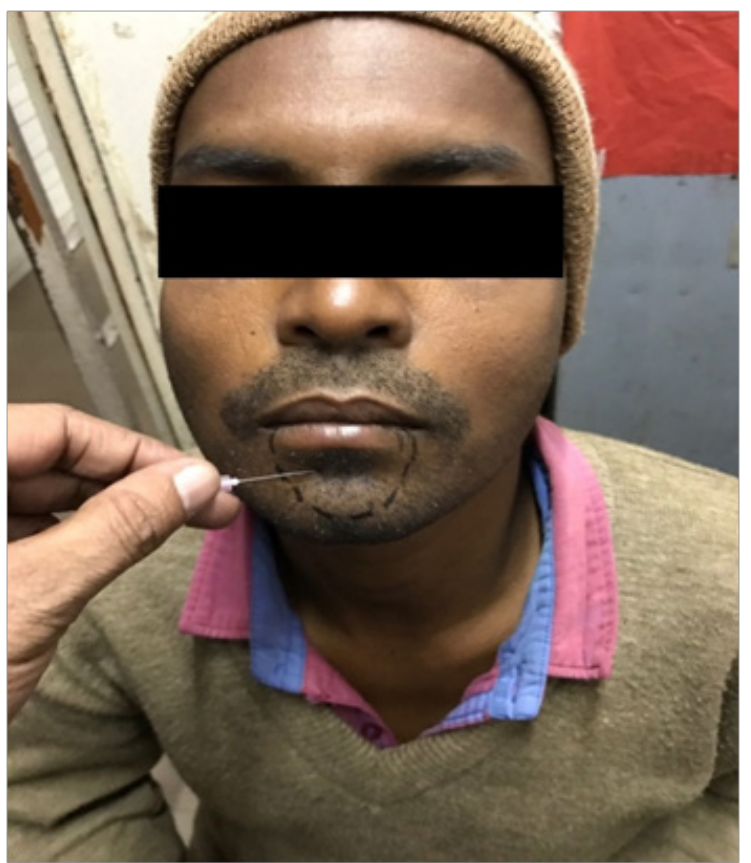

Figure 3 Showing area of anaesthesia as shown by decreased pain sensation to needle prick in case 2 .

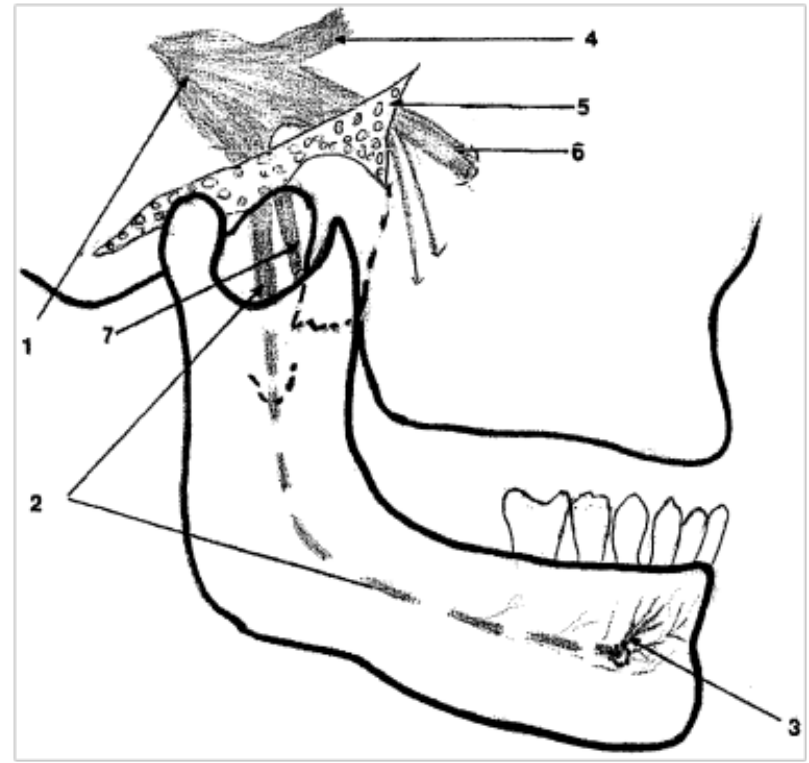

Figure 4 View of the mental nerve from the gasserian ganglion. (I) To the alveolar nerve. (2) And the mental nerve. (3) The mandibular nerveexits the base of the skull via the foramen ovale through the sphenoid. (4) Ophthalmic nerve. (5) The posterior trunk divides and gives the lingual. (6) Maxillary nerve. (7) And The inferior alveolar nerve enters the mandibular canal in the mandible and the mental nerve emerges from the mandibular foramen, at the level of the canine teeth.
In the year 1972, NCS has been reported for the first time among patients of SCD during crisis. ${ }^{2}$ Since then, only 10 cases have been described. ${ }^{4-9}$ In all cases, the syndrome usually appears suddenly, as a complication of crisis, and is associated with bone pain involving the ipsilateral mandible. ${ }^{6-8}$ It was the first presenting feature in a patient with undiagnosed SCD. ${ }^{5}$ Neuroimaging was normal except in one case showing abnormal MRI that included increased T2 signal in both mandibular rami with small sub-periosteal fluid collection that did not enhance on T1 image with contrast. ${ }^{6}$ However, in other cases no MRI abnormality was detected ${ }^{5}$. In our case series we did not find any abnormality in MRI and CT scan.

The first patient reported here experienced short episodes of lower lip numbness during acute sickle cell crises, even when mandibular pain was not prominent. The second case occurred after 15 days of vaso-occlusive crisis. In SCD, recovery of NCS was slow and usually took 1 month to 18 months with a median of 6 months. Hence, the second case probably has developed NCS during crisis and was not detected due to severe pain at other sites. After pain subsided, analgesia was detected by the patient and he sought medical advice. It has been hypothesized that the infarction of the nerve in the region of the mental foramen during the crisis is the cause of delayed recovery. ${ }^{6-8}$ It is usually unilateral but there may be bilateral involvement in $1 / 3 \mathrm{rd}$ cases. ${ }^{4}$ Both the cases reported here had bilateral involvement.

Anatomical peculiarity of inferior alveolar nerve in the mandible is the cause NCS. Mandible is less vascular compared to other bones. The inferior alveolar artery enters the mandible along with the nerve and mental artery also emerges along with the mental nerve through mental foramen. Mental nerve has an unusual bending course making it vulnerable to vascular injury. In SCD, during crisis abnormal RBC block the artery causing ischaemia and infarction of the mental nerve at or near the mental foramen. Apart from ischaemia, compression of inferior alveolar nerve by inflammation of periosteum in the mandibular canal is also another mechanism of NCS.,

\section{Acknowledgments}

None.

\section{Conflicts of interest}

The author declares no conflicts of interest.

\section{References}

1. Serjeant GR, Serjeant BE. Nomenclature and genetics of sickle cell disease, In Sickle Cell Disease, Oxford Univ Press, 3rd ed. 2001:31-38.

2. Konotey-Ahulu FI. Mental-nerve neuropathy: a complication of sickle cell crisis. Lancet. 1972;2(7773):388.

3. Laurencet FM, Anchisi S, Tullen E, et al. Mental neuropathy: report of five cases and review of the literature. Crit Rev Oncol Hematol.2000;34(1):71-79.

4. Erdogan O, Kisa HI, Charudilka S. Sickle-Cell disease: a review of oral manifestation and presentation of a case with an uncommon complication of the disease. Rang J Arts \& Sci. 2013;3:179-185.

5. Mestoudjian P, Steichen O, Stankovic K, et al. Sickle-Cell disease, a benign cause of Numb Chin Syndrome. Am J Med. 2008. 121(10):e1.

6. Hamdoun E, Davis L, McCrary JS, et al. Bilateral mental nerve neuropathy in an adolescent during sickle cell crises. J Child Neurol. 2012;27:10381041. 
7. Friedlander AH, Genser L, Swerdloff M. Mental nerve neuropathy: a complication of sickle cell crisis. Oral Surg Oral Med Oral Path. 1980;49(1):15-17.

8. Kirson LE, Tomaro AJ. Mental nerve paresthesia secondary to sickle cell crisis. Oral Surg Oral Med Oral Path. 1979;48:509-512.
9. Seeler RA, Royal JE. Mental nerve neuropathy in a child with sickle cell anaemia. Am J Ped HematolOncol. 1982;4(2):212-213.

10. Furukawa T. Charles bell's description of numb chin syndrome. Neurology. 1988;38:331. 